\title{
Influences of Contact Pressure on the Performances of Polymer Electrolyte Fuel Cells
}

\author{
Prakash C. Ghosh \\ Department Energy Science and Engineering, Indian Institute of Technology Bombay, Mumbai 400076, India \\ Correspondence should be addressed to Prakash C. Ghosh; pcghosh@iitb.ac.in
}

Received 3 February 2013; Revised 13 May 2013; Accepted 18 May 2013

Academic Editor: Ching Yuan Chang

Copyright ( 2013 Prakash C. Ghosh. This is an open access article distributed under the Creative Commons Attribution License, which permits unrestricted use, distribution, and reproduction in any medium, provided the original work is properly cited.

\begin{abstract}
Fuel cells face major challenges in sustaining the laboratory-scale performance during the scale up. The contact resistance mainly arises from the dimensional mismatch between gasket and gas diffusion layer during scale up, which may cause diminution in performance. In the present work, experiment as well as modelling is carried out for different combinations of clamping force and gasket thickness. The polarisation behaviours of PEFCs configured under different clamping torques and gasket thicknesses are analysed. The combination of $0.3 \mathrm{~mm}$ gasket and $0.3 \mathrm{~mm}$ GDL under $3 \mathrm{Nm}$ and $5 \mathrm{Nm}$ clamping forces offers $480 \mathrm{~m} \Omega \mathrm{cm}^{2}$ and $148 \mathrm{~m} \Omega \mathrm{cm}^{2}$ contact resistances, respectively. The configurations under $3 \mathrm{Nm}$ and $5 \mathrm{Nm}$ clamping torques with $0.2 \mathrm{~mm}$ thick gasket offer contact resistances as low as $23 \mathrm{~m} \Omega \mathrm{cm}^{2}$ and $11 \mathrm{~m} \Omega \mathrm{cm}^{2}$, respectively. The polarisation behaviour obtained from the experiment of such configurations is found to be in good agreement with the modelling results.
\end{abstract}

\section{Introduction}

Fuel cells show great promises in the field of portable, transport and stationary applications [1-3]. They show excellent current voltage characteristics in laboratory-scale cell. However, researchers encounter challenges during scale up due to the heterogeneous local performances inside the fuel cells [4-6]. The local performance is influenced by the operating conditions such as humidity, temperature, and reactant pressure [7-9]. Assembly parameters such as clamping force and gasket thickness influence the local and overall performances. The contact resistance that mainly arises from the dimensional mismatch between the gasket and gas diffusion layer (GDL) plays a significant role in overall performance of the polymer electrolyte fuel cell.

Among different components, mainly matching in the thicknesses of the gasket and the GDL is important to achieve best performance in the fuel cells. Mismatch may lead to the following problems as illustrated in Figure 1.

(i) Thinner gasket may lead to sealing problem causing safety issue. In addition to that, the cell will be facing mass transport-related losses ( Figure 1(b)).

(ii) On the other hand, thicker gasket may result in poor contact between the bipolar plate (BPP) and the GDL, causing a rise in the contact resistance in the cell which will be reflected on the ohmic region of the current voltage characteristics (Figure 1(c)).

Hence, it is important to achieve optimum matching between the gasket and the GDL used in polymer electrolyte fuel cells. During the last decade, researchers focused on estimating the contact resistance, the polymer electrolyte fuel cells (PEFCs) [11] as well as solid oxide fuel cells (SOFCs) [12, 13]. Mishra et al. [14] presented a generalized fractal asperity-based model to predict the contact resistances as a function of contact pressure, material properties, and surface morphology at the interface. Nitta et al. [15] developed a 3D model to analyse the effect of compression pressure on fuel cell, and Liu et al. [16] studied the contact pressure distribution as a function of assembly parameter using response surface methodology (RSM). Su et al. [17] and Lee et al. [18] simulated the contact pressure distribution on the membrane electrode assembly (MEA) of the fuel cell for various assembly pressures. Chang et al. [19] studied the long-term effects of the clamping pressure on the performance of the PEFCs. Zhou et al. [20] investigated the effect of clamping force on the interfacial contact resistance and the porosity of the gas diffusion layer (GDL) in a PEFC. Barber et al. [21] studied the clamping force and the interfacial morphology on interfacial contact 


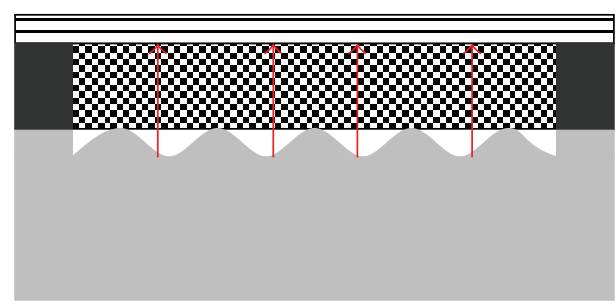

(a)

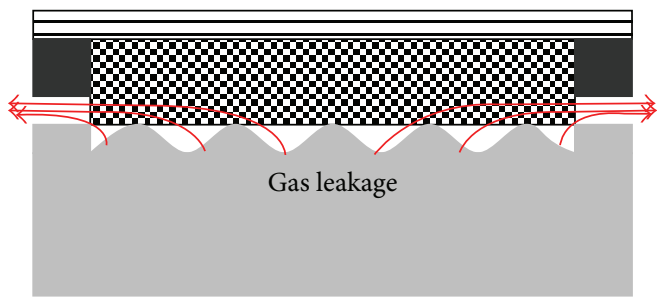

(b)

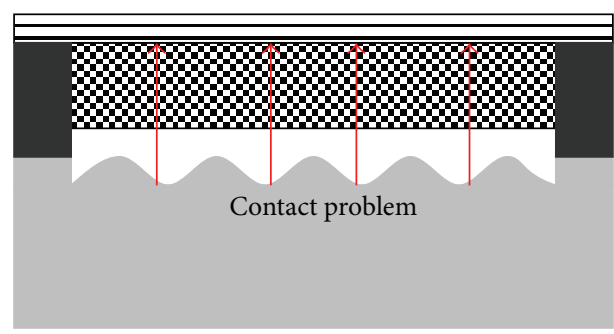

Membrane electrode assembly (MEA)

Gas diffusion layer (GDL)

Gasket

Bipolar plate

(c)

FIGURE 1: Schematic diagram of a half-cell configuration: (a) optimum, (b) with thinner gasket, and (c) with thicker gasket.

area. Xing et al. [22] estimated the optimum clamping force as a function of the operating voltages. The variation in the clamping pressure arising from the aging of the backbone of the gasket is studied [23]. Wang et al. [24] used pressure sensitive films between the MEA and the diffusion layer of a PEFC to study the effect of the end plates on the pressure distribution. Though extensive works are carried out on contact pressure inside fuel cell, author has not come across any study relating the dimensional mismatch between the GDL and gasket and performance of the fuel cells.

The present study aims at investigating the influences of the gasket system and the clamping forces on the performances of the PEFCs. In this purpose, the contact pressure distribution on the electrode surface is measured, and the area-specific contact resistances are estimated to model the performance and validated with experimental results.

\section{Experimental Setup}

Experimental setup consists of contact pressure measurement unit, single polymer electrolyte fuel cell, and leakage test setup unit. Commercially available pressure sensitive films are used to analyse the pressure distributions at the interfaces of different components inside the fuel cell as discussed below.

2.1. Cell Configuration. A polymer electrolyte fuel cell with an outer dimension of $13.5 \times 13.5 \mathrm{~cm}^{2}$ with an active area of $10 \times$ $10 \mathrm{~cm}^{2}$ is used for the present study. The flow fields on both electrodes consist of eight parallel serpentine channel of $1 \times$ $1 \mathrm{~mm}^{2}$ cross-sectional area incorporated on graphite bipolar plate. The MEA consists of cathode and anode electrode with platinum loading of $0.20 \mathrm{mg} \mathrm{cm}^{-2}$ and $0.18 \mathrm{mg} \mathrm{cm}^{-2}$, respectively. Toray carbon paper, TGP-120, of $0.3 \mathrm{~mm}$ thickness is used as GDL on both the electrodes, and perfluorosulfonic acid- (PFSA-) based membrane of thickness $183 \mu \mathrm{m}$ is used as electrolyte. Silicon ( $0.5 \mathrm{~mm}$ thick), flexible graphite $(0.3 \mathrm{~mm}$ and $0.5 \mathrm{~mm}$ thick), and polytetrafluoroethylene (PTFE) $(0.2 \mathrm{~mm}, 0.3 \mathrm{~mm}$, and $0.4 \mathrm{~mm}$ thick) are explored as gasket materials for interfacial contact pressure distribution analysis. The complete cell is assembled by sandwiching all the components between a pair of end plates (SS 316) using sixteen nut bolts of $6 \mathrm{~mm}$ diameter as shown in Figure 2(a). In the present geometry, since the gasket is placed at the periphery of the cell, they have been arranged around the cell.

2.2. Contact Pressure. Commercially available pressure sensitive films (Fujifilm, Prescale LLLW) effective in the pressure range from $0.2 \mathrm{MPa}$ to $2.5 \mathrm{MPa}$ are explored to map the interfacial pressure. The impressions obtained on the film are calibrated with the help of the standard software available with it, and the interfacial contact pressure distributions are estimated. During the assembly, mismatch in the thickness of the gasket and combined thickness of the electrode and GDL mainly leads to the overall resistance. Hence, the pressure sensitive films are placed between the gasket and the bipolar plate to acquire the pressure distribution between the GDL and BPP as shown in Figure 2.

2.3. Gas Sealing Characterisation. Since the actual operations of PEFCs involve hydrogen gas, proper sealing must be ensured before bringing into operation. Hydrogen-operated PEFCs pose two different types of safety concerns-escape of hydrogen from the fuel cell due to the improper sealing and mixing of hydrogen with oxygen/air inside the cell due to the defect (puncture) in the membrane. In the present investigation, an arrangement (Figure 3 ) is made to test the leak and puncture prior to the actual cell operation. The experimental setup is first explored to quantify the gas leakage from the cell followed by puncture test. Initially, the setup is calibrated by closing both the outlets without connecting them to fuel cell. Nitrogen/air is initially introduced in the system through the pressure regulator keeping all the ball valves in opened condition and all the needle valves in closed condition. The pressure is being controlled to achieve the actual operating condition of the fuel cell. Subsequently, the ball valves 2 and 3 are closed, and the variation in both pressure gauges is recorded with time to estimate the leakage in the setup. On achieving satisfactory sealing in the 


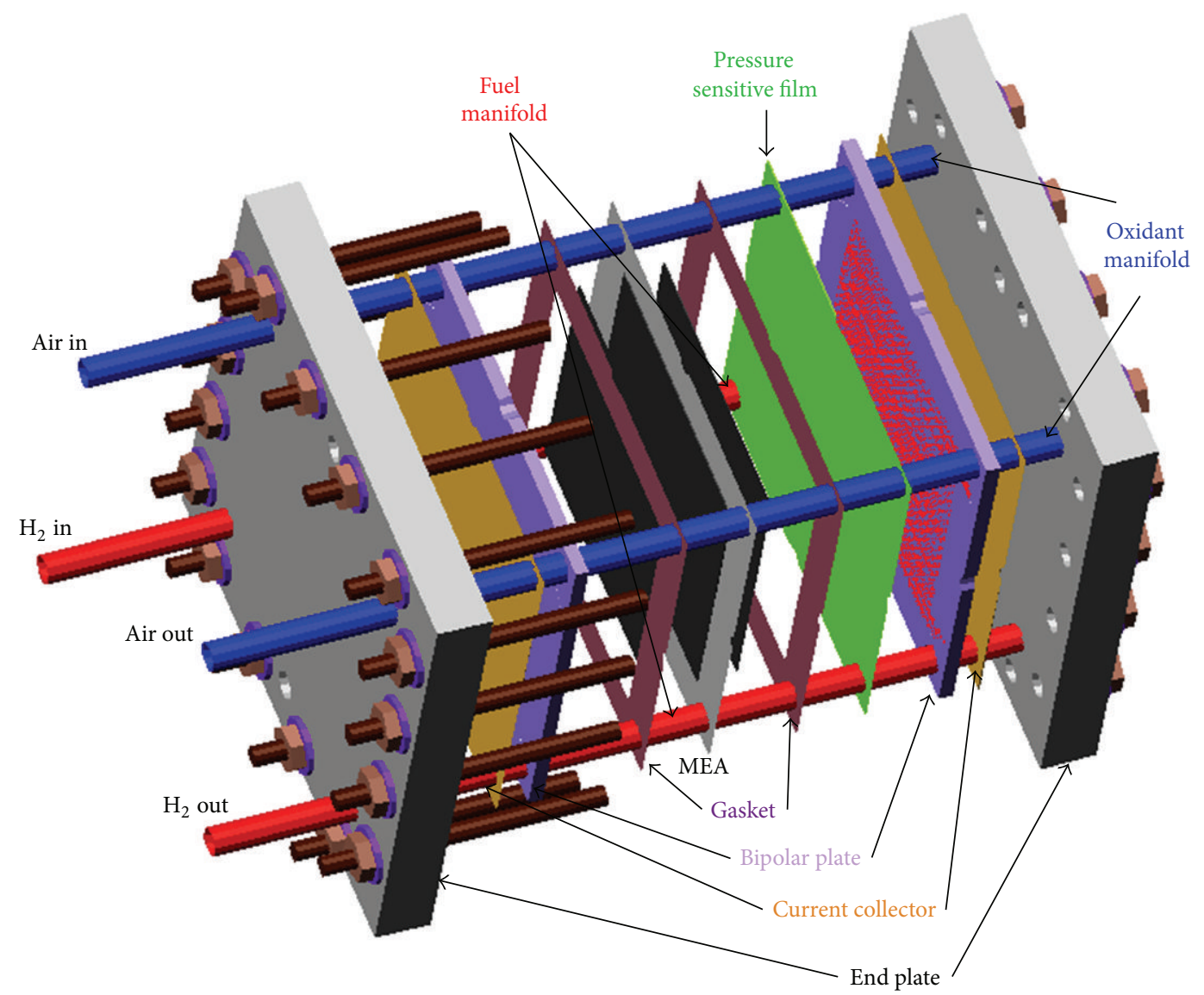

(a)

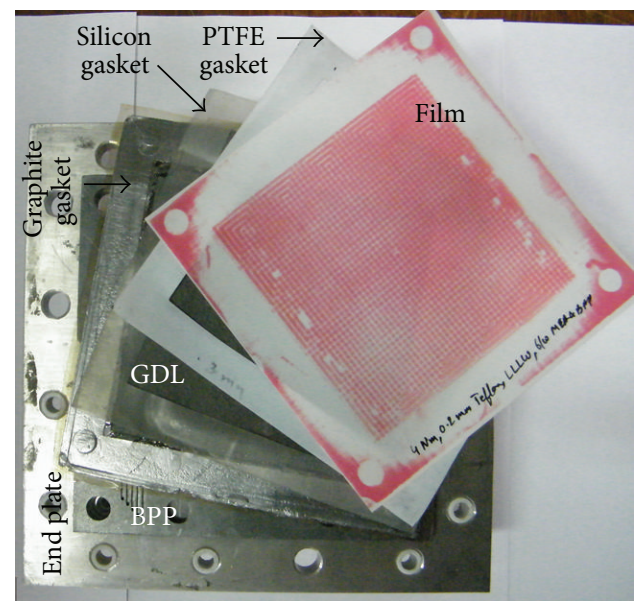

(b)

FIGURE 2: Experimental setup: (a) schematic diagram of the fuel cell with the pressure sensitive film and (b) fuel cell components.

experimental setup, it is connected to the gas inlets (anode and cathode) of the fuel cell assembly keeping the outlets at closed condition as shown in Figure 3. Afterward, the abovementioned procedure of calibration is repeated with fuel cell assembly, and the variations in both pressure gauges are recorded with time to estimate the leakage in the setup.
On achieving satisfactory sealing in the fuel cell, the puncture test is being performed by applying a differential pressure across the membrane. For this purpose, one of the needle valve is being slightly opened for a short while to vent small amount of nitrogen from one side of the fuel cell assembly to develop the differential pressure. 


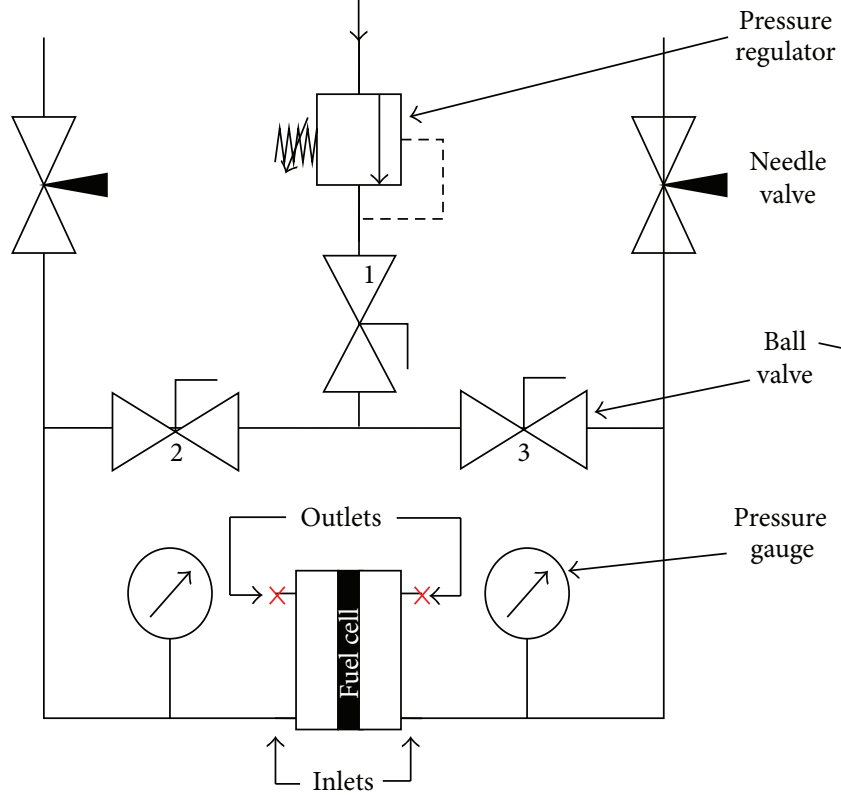

(a)

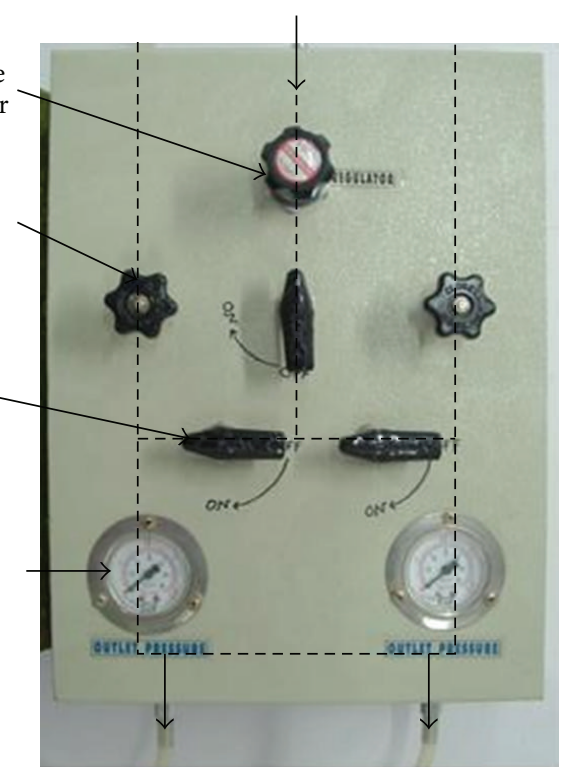

(b)

FiguRE 3: Experimental arrangement for leak and puncture test: (a) schematic diagram and (b) hardware.

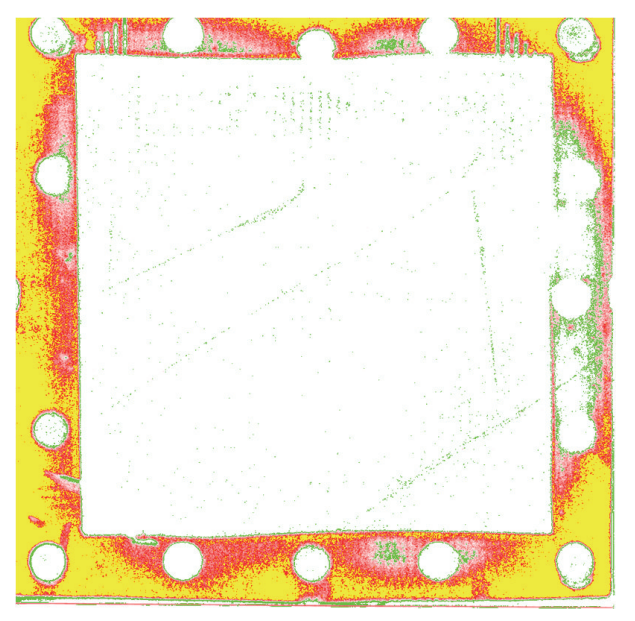

FIgURE 4: Pressure distribution between BPP and GDL under $5 \mathrm{Nm}$ torque for $0.4 \mathrm{~mm}$ gasket [10].

\section{Modelling}

Performances of PEFCs are affected by activation loss, concentration loss, and ohmic loss. The activation overpotential is given by

$$
\eta_{\mathrm{act}}=\frac{R T}{\alpha \cdot n \cdot F} \ln \left(\frac{i}{i_{o}}\right) .
$$

The overpotential arising from concentration loss is given by

$$
\eta_{\text {con }}=-\frac{R T}{n \cdot F} \ln \left(1-\frac{i}{i_{L}}\right) .
$$

The ohmic overpotential is given by

$$
\eta_{\mathrm{ohm}}=i \cdot r
$$

where $r$ is the internal area-specific resistance (ASR) of the fuel cell, which is originated from bulk resistances $\left(r_{b}\right)$ of the components used in fuel cell and contact resistances $\left(r_{c}\right)$ between the adjacent components as expressed below:

$$
r=r_{c}+r_{b}
$$

where

$$
r_{c}=r_{\mathrm{GDL} / \mathrm{BPP}}+r_{\mathrm{BPP} / \mathrm{EP}} .
$$

Among all the components, the ionic resistance of the electrolyte contributes with the lion's share in the bulk resistance of the of the cell. Hence, the area-specific bulk resistance can be estimated, neglecting the contribution of the electronic conductor as follows:

$$
r_{b}=r_{\mathrm{MEM}}=\frac{L}{\sigma}
$$

The contact between the gas diffusion layer and the bipolar plate becomes poor due to the mismatch in the thicknesses of the gasket and the GDL leading to very high internal resistance. The contact resistance at the interface can be estimated from contact pressure $\left(P_{\text {interface }}\right)$ using following expression:

$$
r_{c}=r^{\prime}+r^{\prime \prime}\left(\frac{1}{P_{\text {interface }}}\right)^{C} .
$$



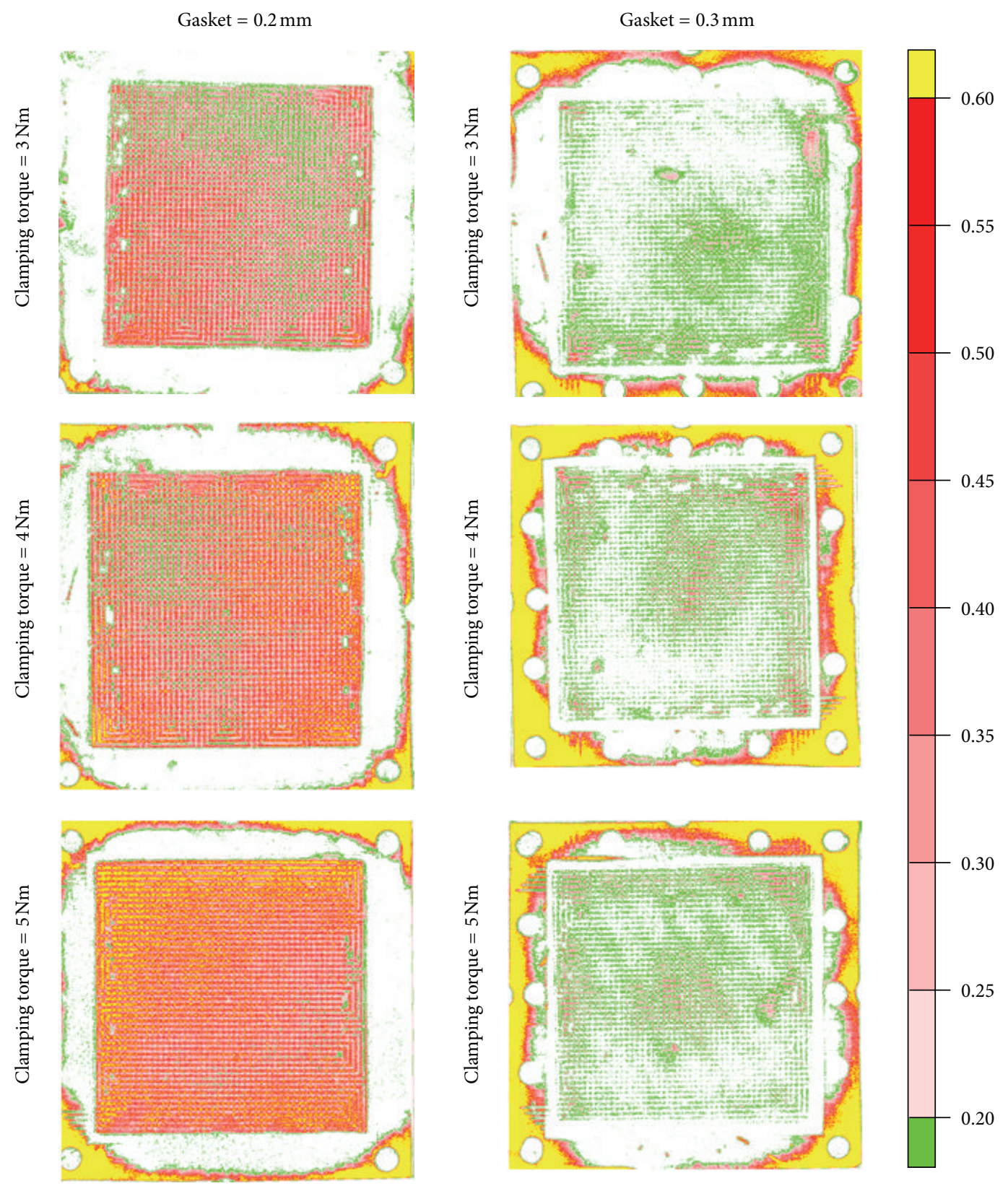

FIGURE 5: Contact pressure distribution (MPa) between GDL and BPP for different configurations.

The polarisation behaviour of a complete cell can be expressed considering all the losses given in (1)-(3) as follows:

$$
\begin{aligned}
E_{\mathrm{rev}}= & E_{\mathrm{rev}}^{o}+\frac{R T}{n \cdot F} \ln \left(\frac{\prod_{i=\text { reactant }}\left(P_{i}\right)^{v_{i}}}{\prod_{j=\text { product }}\left(P_{j}\right)^{v_{j}}}\right) \\
& -\frac{R T}{\alpha \cdot n \cdot F} \ln \left(\frac{i}{i_{o}}\right)-i \cdot r+\frac{R T}{n \cdot F} \ln \left(1-\frac{i}{i_{L}}\right) .
\end{aligned}
$$

\section{Results and Discussions}

The fuel cell is assembled by applying three different clamping torques of $3 \mathrm{Nm}, 4 \mathrm{Nm}$, and $5 \mathrm{Nm}$ which ensure clamping forces of $5.95 \mathrm{kN}, 8.14 \mathrm{kN}$, and $11.18 \mathrm{kN}$, respectively, and the influences of the clamping force on the contact pressure distribution are analysed. In addition, the effect of the gasket thickness is investigated in the present study. The areaspecific contact resistances (ASCRs) at the interfaces are modelled based on the measured contact pressure distributions. The sealing qualities for different gaskets are analysed and pertinently sealed fuel cell assemblies are picked out for polarisation analysis. The effect of the gasket thickness and the clamping force on the polarisation behaviour is studied and modelled.

4.1. Contact Pressure Distribution. PTFE gaskets with thickness of $0.2 \mathrm{~mm}, 0.3 \mathrm{~mm}$, and $0.4 \mathrm{~mm}$ are preferred to assembling the cell because the thickness of the GDL is $0.3 \mathrm{~mm}$. 


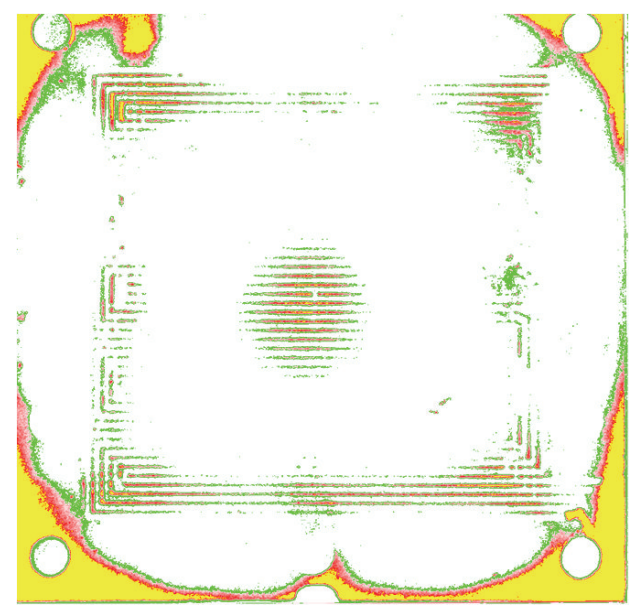

(a)

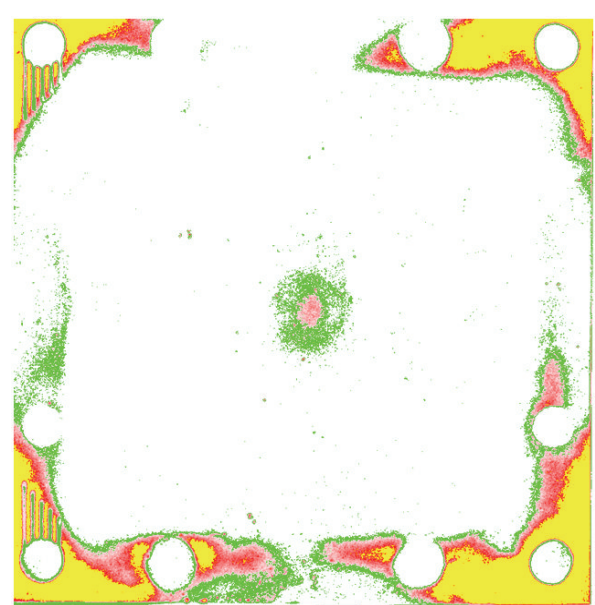

(b)

Figure 6: Contact pressure distribution (MPa) between (a) BPP and end plate and (b) two end plates.

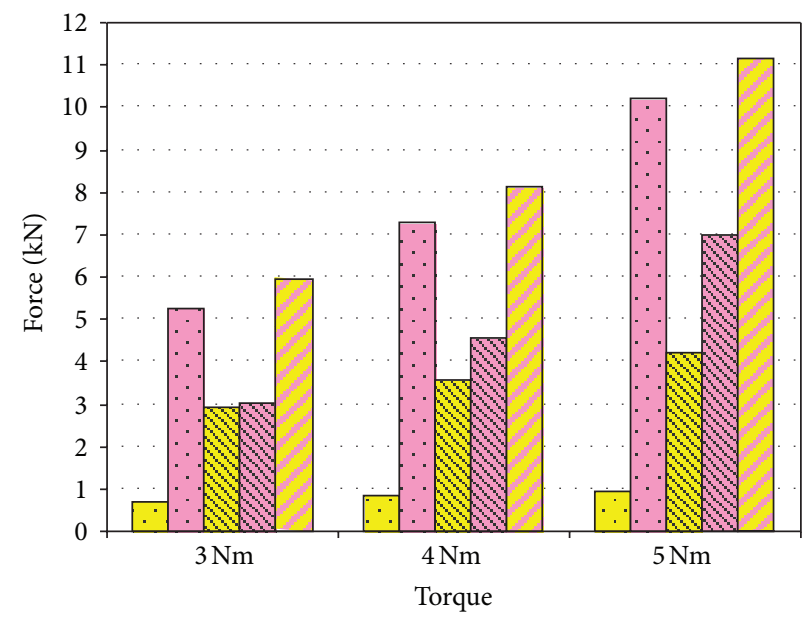

0 Electrode and 0.3

Electrode and 0.2

$\square$ Total

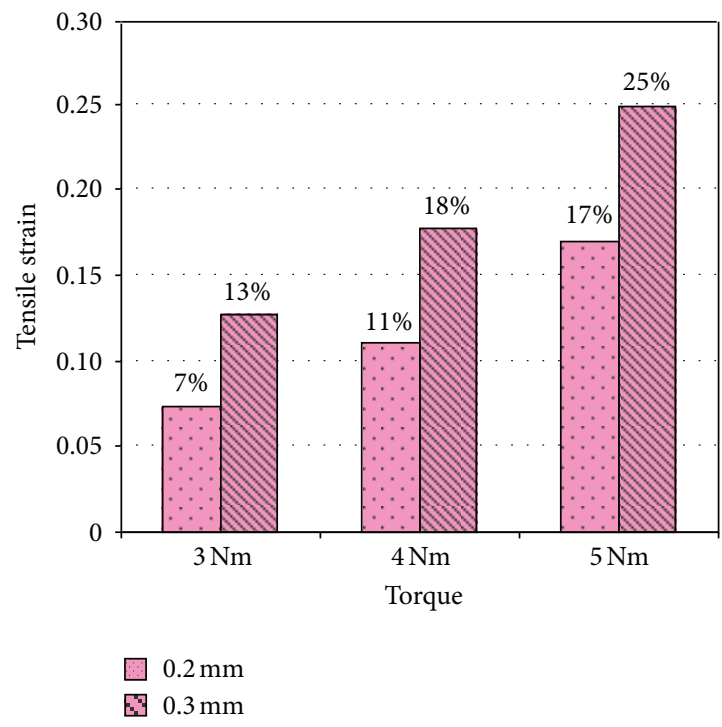

(b)

FIGURE 7: (a) Clamping force and (b) tensile strain of the PTFE gasket under different configurations.

It is observed that the assembly with $0.4 \mathrm{~mm}$ gasket fails to develop sufficient contact at the interface of GDL and BPP, and no impression other than the gasket is obtained on the pressure film as shown in Figure 4. Similar effects are observed in case of silicon and expanded graphite gasket. Hence, gaskets with thicknesses equal to $0.4 \mathrm{~mm}$ or more are discarded in further analysis. Hence, further analysis is carried out with PTFE gasket of thickness $0.3 \mathrm{~mm}$ and $0.2 \mathrm{~mm}$ and $0.3 \mathrm{~mm}$ expanded graphite.

In Figure 5, the contact pressure distribution between the BPP and GDL is shown for different clamping forces with $0.2 \mathrm{~mm}$ and $0.3 \mathrm{~mm}$ gaskets. The contact pressure distribution on the electrode surface is prominent for the gasket with $0.2 \mathrm{~mm}$ thickness. However, the impression of the gasket is not prominent, and it may result in poor reactant sealing. The assembly with $0.3 \mathrm{~mm}$ gasket provides very good sealing as the contact pressure distribution reaches to the maximum limit of the film. However, it fails to generate sufficient contact pressure on the electrode surface. Most of the regions experience pressures close to the lower range of the film, and some of the regions even experience pressure in the ranges below the minimum limit of the film causing no impression.

Generally, it is expected that the pressure in the middle should be minimum and increases as it approaches the edges. However, it is observed that the contact pressure is relatively higher at the centre of the electrode area in addition to the edges. It could be attributed to the marginal mechanical defect in machining the end plate resulted in 


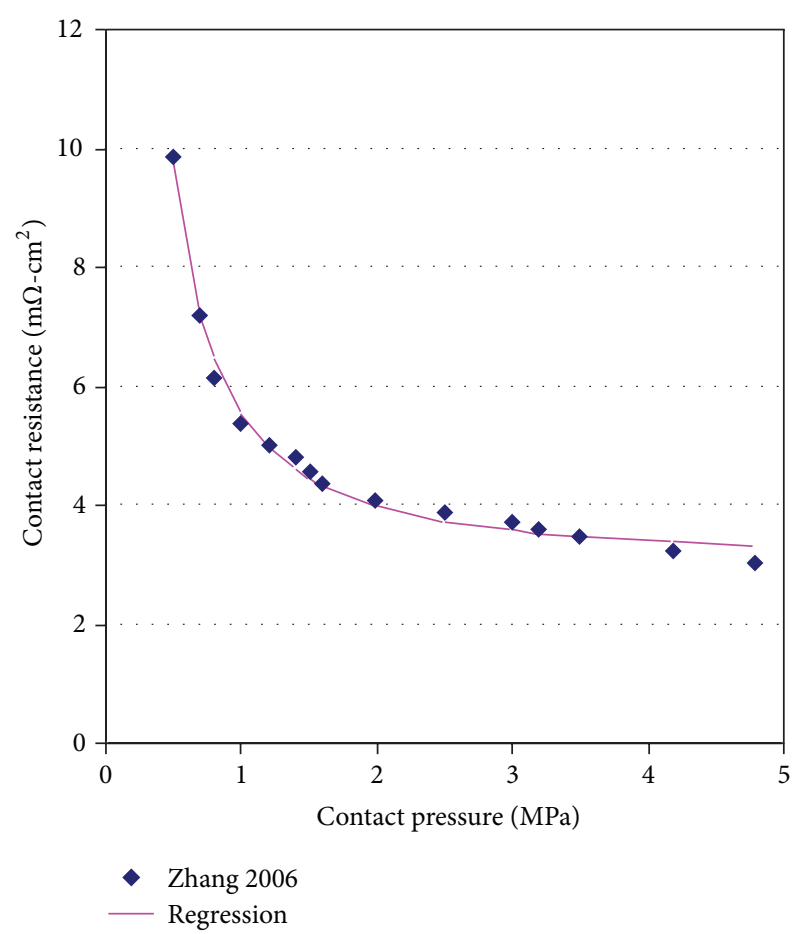

FIGURE 8: Modelling of contact resistance at the BPP and GDL interface.

slight uneven surface. The pressure distribution obtained only with end plates, and the BPPs are shown in Figure 6, which confirms the fact of machining defect. The present assembly with clamping forces around the fuel cell with a slight thicker dimension at the centre of the BPP helps to achieve relatively uniform clamping force distribution.

The share of the total clamping force, GDL, and gasket at different tightening torque is shown in Figure 7(a). For both gaskets, though the overall contact pressure increases with the increase in the clamping force, the share of the GDL decreases. In case of $0.2 \mathrm{~mm}$ gasket, the proportion of the force on GDL decreases from $49 \%$ to $38 \%$, whereas, in case of $0.3 \mathrm{~mm}$ gasket, it decreases from $12 \%$ to $8 \%$. Hence, it is clear that the lion's share of the force is translated to the gasket. In Figure 7(b), the tensile strains of the gaskets for different configurations are estimated considering the Young modulus of PTFE equal to $0.5 \mathrm{GPa}$.

4.2. Contact Resistance Distribution. The ASCR at the interface is modelled based on the experimental results reported by Zhang et al. [25] as shown in Figure 8. The variation in contact resistances with the contact pressure between the BPP and the carbon paper is modelled by regression analysis based on (8), which produces $R^{2}$ value of 0.992 for $r^{\prime}=3.05, r^{\prime \prime}=$ 2.464, and $c=1.418$.

Based on the above-mentioned model, the average value of ASCR between the BPP and the GDL is estimated for different configurations as shown in Figure 9. The ASCR is found to be around $23 \mathrm{~m} \Omega \mathrm{cm}^{2}$ and $11 \mathrm{~m} \Omega \mathrm{cm}^{2}$ for assembly with $0.2 \mathrm{~mm}$ thick gasket under $3 \mathrm{Nm}$ and $5 \mathrm{Nm}$, respectively. However, assembly with $0.3 \mathrm{~mm}$ gasket produces average

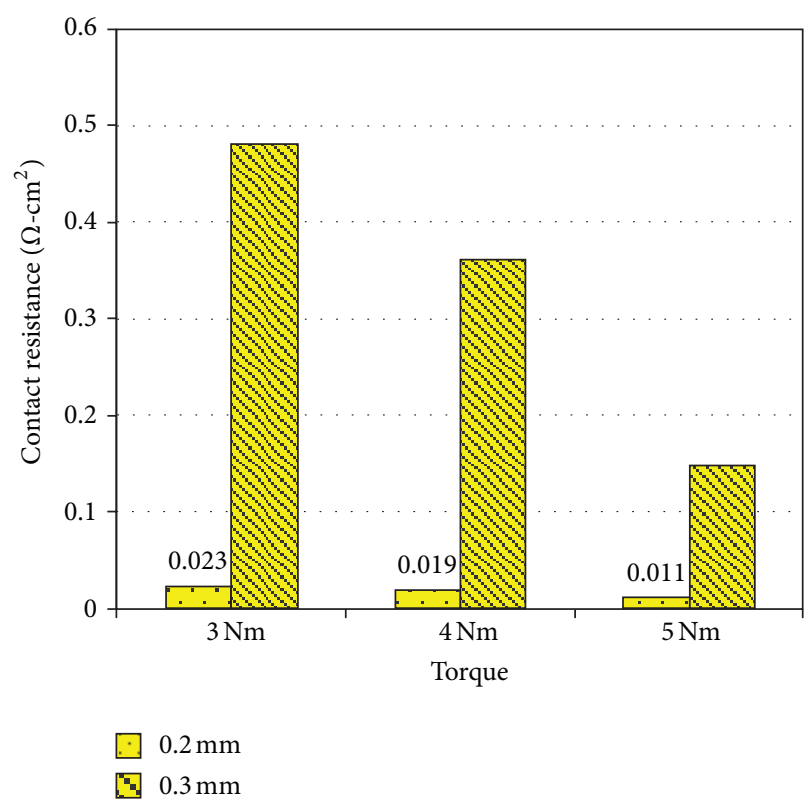

FIGURE 9: Contact resistances between the GDL and the BPP for different configurations.

ASCR around $480 \mathrm{~m} \Omega \mathrm{cm}^{2}$ and $148 \mathrm{~m} \Omega \mathrm{cm}^{2}$, under $3 \mathrm{Nm}$ and $5 \mathrm{Nm}$, respectively. Hence, the contribution of interfacial contact resistance with $0.3 \mathrm{~mm}$ gasket assembly to the internal resistance becomes significant.

The ASCR distributions at the interface between the GDL and the BPP corresponding to Figure 5 are shown in Figure 10. It shows that a substantial portion of the GDL surface in the configuration with $0.3 \mathrm{~mm}$ gasket has very high resistance or no contact between the GDL and the BPP. On the other hand, assembly with $0.2 \mathrm{~mm}$ gasket generates homogeneous contact resistance on the GDL surface.

4.3. Sealing Test. The pressure film is removed from the configuration, presented in Figure 2(a), for studying the sealing and polarisation performance and assembled under different configurations as given in Figure 5. Sealing tests of the different configurations are carried out prior to the activation of the fuel cell with hydrogen and air for evaluating the polarisation characteristics. Initially, both chambers of the fuel cell are filled with air at $200 \mathrm{mbar}$ (gauge), and subsequently, the variation in the gauge pressure is recorded. The leak test performances of the fuel cells at different configurations are shown in Figure 11. The configuration with $0.3 \mathrm{~mm}$ gasket under $5 \mathrm{Nm}$ torque exhibits best sealing behaviour compared to the other configurations. Results obtained from the leak tests agree with the contact pressure distribution in Figure 5. Thus, the assembly $0.2 \mathrm{~mm}$ only under $5 \mathrm{Nm}$ torque and all the assemblies with $0.3 \mathrm{~mm}$ gasket are considered for actual polarisation tests.

4.4. Polarization Behaviour. During the present investigations, the polarisation behaviour is analysed with hydrogen as fuel and air as oxidant. Humidified hydrogen and oxygen with dew point $40^{\circ} \mathrm{C}$ are fed at constant flow rates of $0.3 \mathrm{Lpm}$ and 

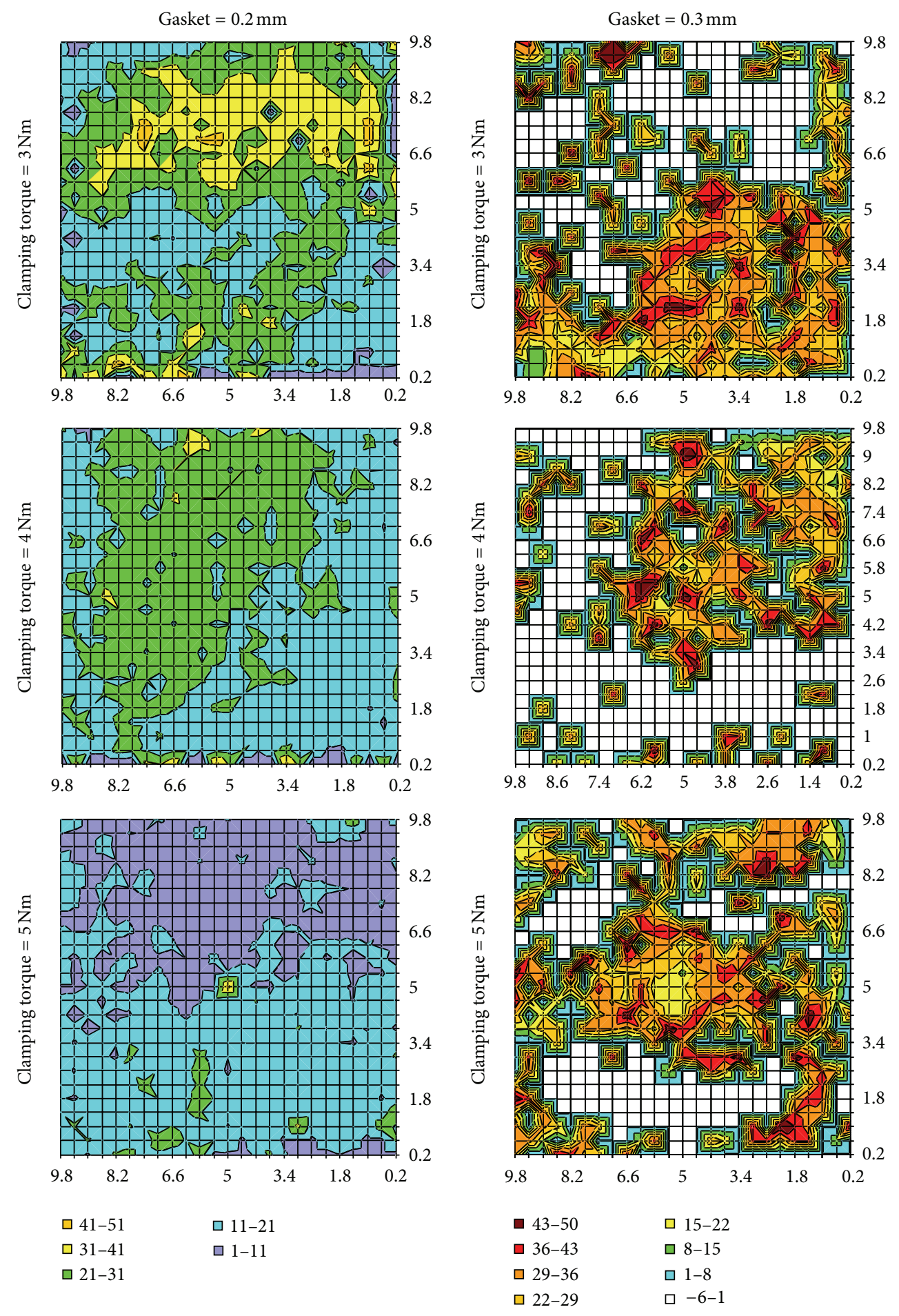

FIGURE 10: Contact resistance distribution $\left(\mathrm{m} \Omega \mathrm{cm}^{2}\right)$ between GDL and BPP for different configurations.

$3 \mathrm{Lpm}$, respectively. As the configuration with $0.2 \mathrm{~mm}$ gasket under $3 \mathrm{Nm}$ and $4 \mathrm{Nm}$ torques exhibits very poor sealing, they are not considered for polarisation behaviour analysis.

The assembly with $0.2 \mathrm{~mm}$ gasket and $5 \mathrm{Nm}$ torque exhibits best polarisation behaviour over other configurations as shown in Figure 12. Though this configuration exhibits relatively poor performance in terms of gas sealing, it offers better performance due to high contact pressure between the $\mathrm{BPP}$ and GDL leading to lower ASCR value compared to the $0.3 \mathrm{~mm}$ gasket. The performance is modelled (7) considering the estimated contact resistances based on measured contact pressures. The parameters used for modelling the polarisation behaviour are given in Table 1. The polarisation behaviours obtained experimentally with $5 \mathrm{Nm}$ torque are found to be 


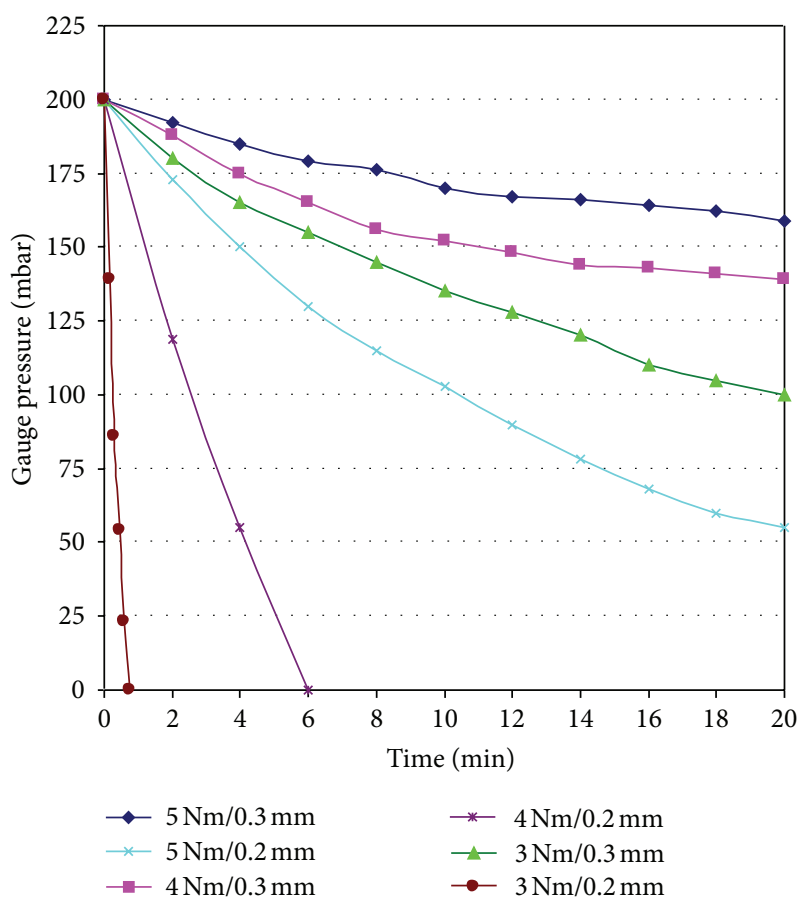

FIGURE 11: Variation in the gauge pressure of air for different fuel cell assembly with PTFE gasket.

in good agreement with the model. However, the assembly with $3 \mathrm{Nm}$ offers relatively poor agreement. This could be due to the error in measuring the interfacial pressure in some regions where pressure lies below the minimum range of the film.

\section{Conclusions}

The influences of the mismatch in the thicknesses of GDL and gasket are investigated. In addition, the influences of the clamping pressure on the performances are also studied. In this purpose, the contact pressure between the GDL and the BPP is measured using pressure sensitive film, and consequently, the area-specific contact resistance is estimated. It is observed that the contact resistance plays significant role in the configuration with $0.3 \mathrm{~mm}$ gasket and $0.3 \mathrm{~mm}$ GDL. Such configuration, under $3 \mathrm{Nm}$ and $5 \mathrm{Nm}$ clamping forces, exhibits $480 \mathrm{~m} \Omega \mathrm{cm}^{2}$ and $148 \mathrm{~m} \Omega \mathrm{cm}^{2}$ contact resistance, respectively. The configurations below $3 \mathrm{Nm}$ and $5 \mathrm{Nm}$ clamping forces and with $0.2 \mathrm{~mm}$ thick gasket exhibits $23 \mathrm{~m} \Omega \mathrm{cm}^{2}$ and $11 \mathrm{~m} \Omega \mathrm{cm}^{2}$ contact resistances, respectively. The polarisation behaviour obtained from the experiment of such configurations agrees with the modelling results.

\section{Nomenclature}

$\alpha$ : Charge transfer coefficient

$\eta_{\text {act }}:$ Activation overpotential (V)

$i$ : Current density normalised based on active area $\left(\mathrm{A} \mathrm{cm}^{-2}\right)$

$i_{o}$ : Exchange current density $\left(\mathrm{A} \mathrm{cm}^{-2}\right)$

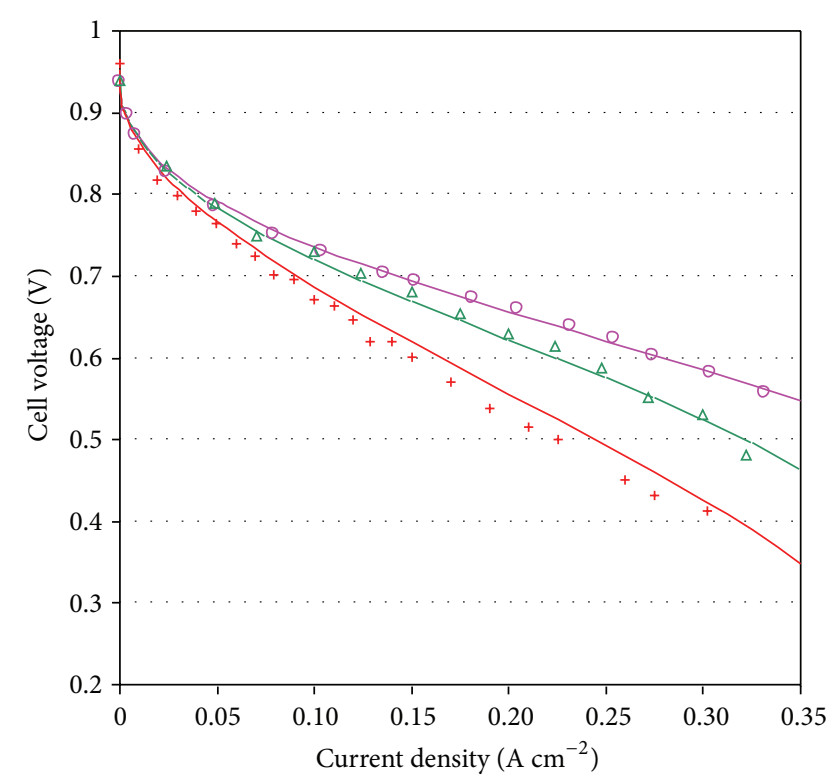

- Expt: $5 \mathrm{Nm}$ and $0.2 \mathrm{~mm} \quad$ Model: $5 \mathrm{Nm}$ and $0.2 \mathrm{~mm}$

$\triangle$ Expt: $5 \mathrm{Nm}$ and $0.3 \mathrm{~mm} \quad$ Model: $5 \mathrm{Nm}$ and $0.3 \mathrm{~mm}$

+ Expt: $3 \mathrm{Nm}$ and $0.3 \mathrm{~mm} \quad$ Model: $3 \mathrm{Nm}$ and $0.3 \mathrm{~mm}$

FIgURE 12: Polarisation behaviour of the fuel cell under different configurations.

$\eta_{\text {con }}: \quad$ Concentration overpotential (V)

$i_{L}: \quad$ Limiting current $\left(\mathrm{A} \mathrm{cm}^{-2}\right)$

$\eta_{\text {ohm }}: \quad$ Ohmic overpotential (V)

$r: \quad$ Area-specific internal resistance $\left(\Omega \mathrm{cm}^{2}\right)$

$r_{c}: \quad$ Internal area-specific contact resistance $\left(\Omega \mathrm{cm}^{2}\right)$

$r_{b}: \quad$ Internal area-specific bulk resistance $\left(\Omega \mathrm{cm}^{2}\right)$

$r_{\mathrm{GDL} / \mathrm{BPP}}$ : Contact resistance between BPP and GDL $\left(\Omega \mathrm{cm}^{2}\right)$

$r_{\mathrm{BPP} / \mathrm{EP}}$ : Contact resistance between BPP and end plate $\left(\Omega \mathrm{cm}^{2}\right)$

$r_{\mathrm{MEM}}$ : Area-specific bulk resistance of membrane $\left(\Omega \mathrm{cm}^{2}\right)$

$r_{\mathrm{EL}}: \quad$ Area-specific bulk resistance of electrode $\left(\Omega \mathrm{cm}^{2}\right)$

$r_{\mathrm{GDL}}: \quad$ Area-specific bulk resistance of GDL $\left(\Omega \mathrm{cm}^{2}\right)$

$r_{\mathrm{BPP}}: \quad$ Area-specific bulk resistance of BPP $\left(\Omega \mathrm{cm}^{2}\right)$

$L: \quad$ Thickness of the membrane $(\mathrm{cm})$

$\sigma: \quad$ Conductivity of membrane $\left(\mathrm{S} \mathrm{cm}^{-1}\right)$

$r^{\prime}$ : $\quad$ Fitting parameter for contact resistance $\left(\Omega \mathrm{cm}^{2}\right)$

$r^{\prime \prime}: \quad$ Fitting parameter for contact resistance $\left(\Omega \mathrm{cm}^{2}\right)$

C: $\quad$ Fitting parameter for contact resistance

$P_{\text {interface }}$ : Contact pressure (MPa)

$\eta_{\text {total }}: \quad$ Overall total overpotential (V)

E: $\quad$ Operating potential $(\mathrm{V})$

$E_{\text {rev }}: \quad$ Reversible electrode potential (V)

$E_{\text {rev }}^{o}: \quad$ Standard electrode potential (V)

$R: \quad$ Universal gas constant $\left(\mathrm{J} \mathrm{mol}^{-1} \mathrm{~K}^{-1}\right)$

$T: \quad$ Operating temperature $(\mathrm{K})$ 
TABLE 1: Parameters used for the modelling of the polarisation behaviours.

\begin{tabular}{lccccccc}
\hline \multirow{2}{*}{ Configuration (torque and thickness) } & \multicolumn{2}{c}{ Activation } & \multicolumn{2}{c}{ Ohmic } & \multicolumn{3}{c}{ Mass transfer } \\
& $A(\mathrm{~V})$ & $i_{o}\left(\mathrm{~mA} \mathrm{~cm}^{-2}\right)$ & $r_{c}\left(\Omega \mathrm{cm}^{2}\right)$ & $\sigma\left(\mathrm{S} \mathrm{cm}^{-1}\right)$ & $r_{b}\left(\Omega \mathrm{cm}^{2}\right)$ & $B(\mathrm{~V})$ & $i_{L}\left(\mathrm{~mA} \mathrm{~cm}^{-2}\right)$ \\
\hline $5 \mathrm{Nm}$ and $0.2 \mathrm{~mm}$ & 0.0525 & 0.3 & 0.011 & 0.06 & 0.305 & 0.045 & 500 \\
$5 \mathrm{Nm}$ and $0.3 \mathrm{~mm}$ & 0.0525 & 0.3 & 0.148 & 0.06 & 0.305 & 0.045 & 450 \\
$3 \mathrm{Nm}$ and $0.3 \mathrm{~mm}$ & 0.0525 & 0.3 & 0.480 & 0.06 & 0.305 & 0.045 & 450 \\
\hline
\end{tabular}

$n$ : Number moles of electrons per mole of fuel (mol)

F: Faraday's constant $\left(\mathrm{C} \mathrm{mol}^{-1}\right)$

$P_{i}$ : Partial pressure of $i$ th specie

$v_{i}$ : Stoichiometric coefficient

for the $i$ th reactant.

\section{Abbreviations}

ASR: Area-specific resistance

ASCR: Area-specific contact resistance

BPP: Bipolar plate

FEA: Finite element analysis

GDL: Gas diffusion layer

MEA: Membrane electrode assembly

PEFC: Polymer electrolyte fuel cell

PFSA: Perfluorosulfonic acid

PTFE: Polytetrafluoroethylene

RSM: Response surface methodology

SOFC: Solid oxide fuel cell.

\section{Acknowledgments}

The work was sponsored by the Naval Material Research Laboratory (NMRL), Defence Research and Development Organisation of India. The support from Dr. J. Rangarajan, Dr. S. Roychowdhuri, and Mrs. Suhasini Roychoudhury of NMRL is acknowledged. The contribution of Mr. Amar Nath in acquiring pressure distributions is also acknowledged.

\section{References}

[1] Y. Wang, K. S. Chen, J. Mishler, S. C. Cho, and X. C. Adroher, "A review of polymer electrolyte membrane fuel cells: technology, applications, and needs on fundamental research," Applied Energy, vol. 88, no. 4, pp. 981-1007, 2011.

[2] B. C. H. Steel and A. Heinze, "Materials for fuel-cell technologies," Nature, vol. 414, pp. 345-352, 2001.

[3] M. S. Dresselhaus and I. L. Thomas, "Alternative energy technologies," Nature, vol. 414, no. 6861, pp. 332-337, 2001.

[4] P. C. Ghosh, T. Wüster, H. Dohle, N. Kimiaie, J. Mergel, and D. Stolten, "Analysis of single PEM fuel cell performances based on current density distribution measurement," Journal of Fuel Cell Science and Technology, vol. 3, no. 3, pp. 351-357, 2006.

[5] I. Alaefour, G. Karimi, K. Jiao, and X. Li, "Measurement of current distribution in a proton exchange membrane fuel cell with various flow arrangements-a parametric study," Applied Energy, vol. 93, pp. 80-89, 2012.

[6] H. Dohle, J. Mergel, and P. C. Ghosh, "DMFC at low air flow operation: study of parasitic hydrogen generation," Electrochimica Acta, vol. 52, no. 19, pp. 6060-6067, 2007.
[7] K. Panha, M. Fowler, X.-Z. Yuan, and H. Wang, "Accelerated durability testing via reactants relative humidity cycling on PEM fuel cells," Applied Energy, vol. 93, pp. 90-97, 2012.

[8] A. Nishimura, K. Shibuya, A. Morimoto et al., "Dominant factor and mechanism of coupling phenomena in single cell of polymer electrolyte fuel cell," Applied Energy, vol. 90, no. 1, pp. 73-79, 2012.

[9] P. C. Ghosh, H. Dohle, and J. Mergel, "Modelling of heterogeneities inside polymer electrolyte fuel cells due to oxidants," International Journal of Hydrogen Energy, vol. 34, no. 19, pp. 8204-8212, 2009.

[10] N. Amar, Contact pressure distribution in polymer electrolyte fuel cell [M. Tech. dissertation], Indian Institute of Technology Bombay, 2010.

[11] J. Ihonen, F. Jaouen, G. Lindbergh, and G. Sundholm, "A novel polymer electrolyte fuel cell for laboratory investigations and in-situ contact resistance measurements," Electrochimica Acta, vol. 46, no. 19, pp. 2899-2911, 2001.

[12] S. P. Jiang, J. G. Love, and L. Apateanu, "Effect of contact between electrode and current collector on the performance of solid oxide fuel cells," Solid State Ionics, vol. 160, no. 1-2, pp. 1526, 2003.

[13] T. Dey, D. Singdeo, M. Bose, R. N. Basu, and P. C. Ghosh, "Study of contact resistance at the electrodeinterconnect interfaces in planar type Solid Oxide Fuel Cells," Journal of Power Sources, vol. 233, pp. 290-298, 2013.

[14] V. Mishra, F. Yang, and R. Pitchumani, "Measurement and prediction of electrical contact resistance between gas diffusion layers and bipolar plate for applications to PEM fuel cells," Journal of Fuel Cell Science and Technology, vol. 1, no. 1, pp. 2-9, 2004.

[15] I. Nitta, O. Himanen, and M. Mikkola, "Contact resistance between gas diffusion layer and catalyst layer of PEM fuel cell," Electrochemistry Communications, vol. 10, no. 1, pp. 47-51, 2008.

[16] D. Liu, L. Peng, and X. Lai, "Effect of assembly error of bipolar plate on the contact pressure distribution and stress failure of membrane electrode assembly in proton exchange membrane fuel cell," Journal of Power Sources, vol. 195, no. 13, pp. 4213-4221, 2010.

[17] Z. Y. Su, C. T. Liu, H. P. Chang, C. H. Li, K. J. Huang, and P. C. Sui, "A numerical investigation of the effects of compression force on PEM fuel cell performance," Journal of Power Sources, vol. 183, no. 1, pp. 182-192, 2008.

[18] S. J. Lee, C. D. Hsu, and C. Huang, "Analyses of the fuel cell stack assembly pressure," Journal of Power Sources, vol. 145, no. 2, pp. 353-361, 2005.

[19] W. R. Chang, J. J. Hwang, F. B. Weng, and S. H. Chan, "Effect of clamping pressure on the performance of a PEM fuel cell," Journal of Power Sources, vol. 166, no. 1, pp. 149-154, 2007.

[20] P. Zhou, C. W. Wu, and G. J. Ma, "Contact resistance prediction and structure optimization of bipolar plates," Journal of Power Sources, vol. 159, no. 2, pp. 1115-1122, 2006. 
[21] M. Barber, T. S. Sun, E. Petrach, X. Wang, and Q. Zou, "Contact mechanics approach to determine contact surface area between bipolar plates and current collector in proton exchange membrane fuel cells," Journal of Power Sources, vol. 185, no. 2, pp. 1252-1256, 2008.

[22] X. Q. Xing, K. W. Lum, H. J. Poh, and Y. L. Wu, "Optimization of assembly clamping pressure on performance of protonexchange membrane fuel cells," Journal of Power Sources, vol. 195, no. 1, pp. 62-68, 2010.

[23] J. Tan, Y. J. Chao, J. W. Van Zee, and W. K. Lee, "Degradation of elastomeric gasket materials in PEM fuel cells," Materials Science and Engineering A, vol. 445-446, pp. 669-675, 2007.

[24] X. Wang, Y. Song, and B. Zhang, "Experimental study on clamping pressure distribution in PEM fuel cells," Journal of Power Sources, vol. 179, no. 1, pp. 305-309, 2008.

[25] L. Zhang, Y. Liu, H. Song, S. Wang, Y. Zhou, and S. J. Hu, “Estimation of contact resistance in proton exchange membrane fuel cells," Journal of Power Sources, vol. 162, no. 2, pp. 1165-1171, 2006. 


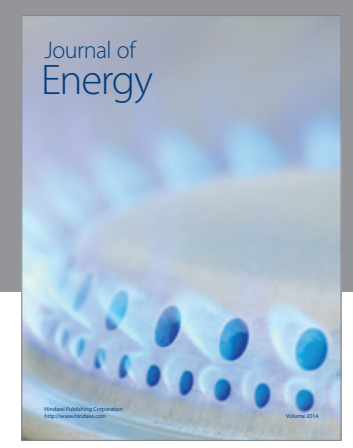

Journal of

Industrial Engineering
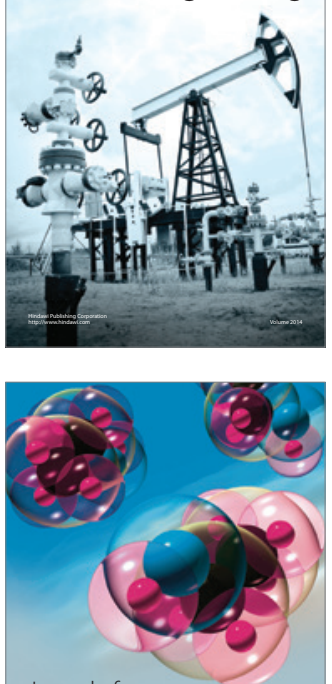

Fuels
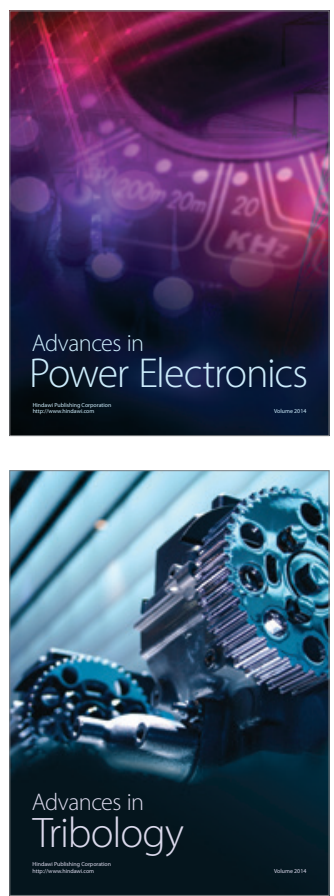

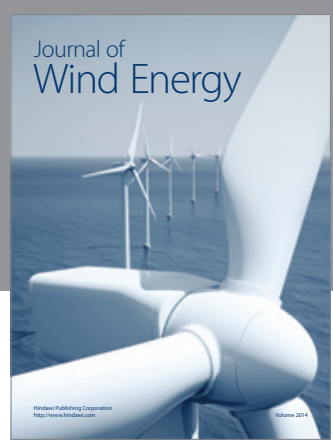

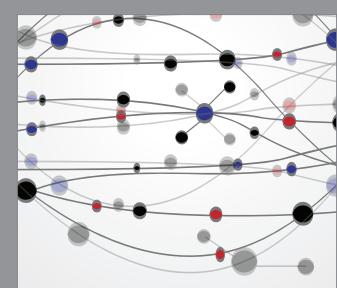

The Scientific World Journal

Submit your manuscripts at http://www.hindawi.com

Journal of

Structures
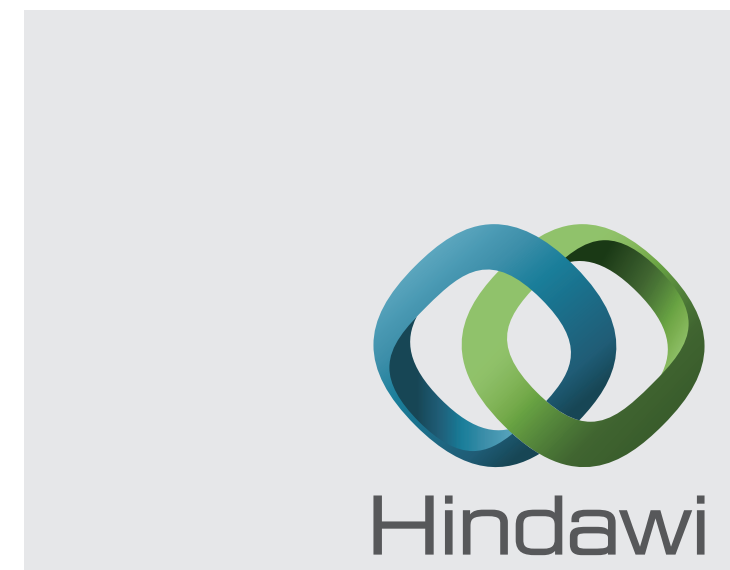

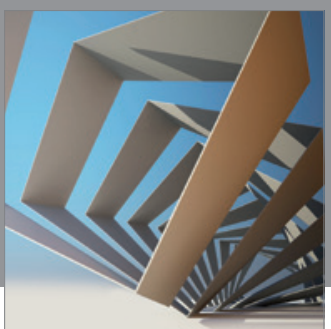

Rotating

Machinery
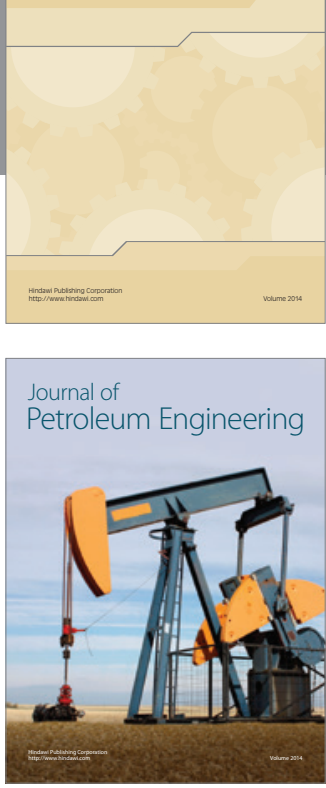

Journal of

Solar Energy
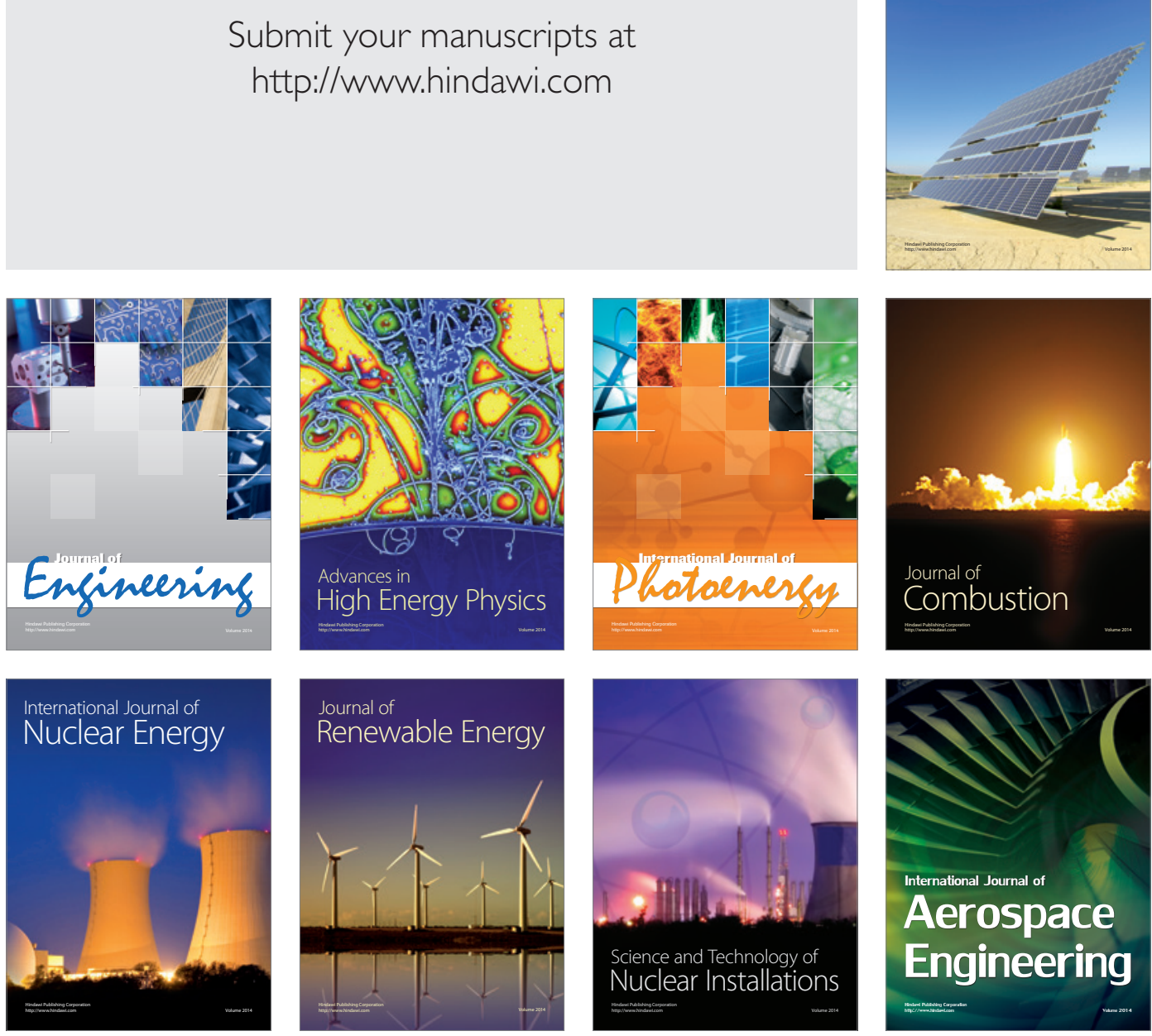